\title{
Erratum to "Valid Geometric Solutions for Indentations with Algebraic Calculations", [Advances in Pure Mathematics, Vol. 10 (2020) 322-336]
}

\author{
Gerd Kaupp \\ University of Oldenburg, Oldenburg, Germany \\ Email: gerd.kaupp@uni-oldenburg.de
}

Received: August 24, 2020

Accepted: September 26, 2020

Published: September 29, 2020

Copyright (c) 2020 by author(s) and Scientific Research Publishing Inc. This work is licensed under the Creative Commons Attribution International License (CC BY 4.0).

http://creativecommons.org/licenses/by/4.0/
The original online version of this article (Gerd Kaupp 2020) Valid Geometric Solutions for Indentations with Algebraic Calculations, (Volume, 10, 322-336, https://doi.org/10.4236/apm.2020.105019) needs some further amendments and clarification.

\section{The Deduction Details for the Spherical Indentations}

\section{Equation}

The incorrect proportionalities (16) and (17) in the published main-text are useless and we apologize for their being printed. They were not part of the deduction of the Equation $\left(18_{v}\right)$. The deduction of $\left(18_{v}\right)$ follows the one for the pyramidal or conical indentations (4) through (8). The only difference is a dimensionless correction factor $\pi(R / h-1 / 3)$ that must be applied to every data pair due to the calotte volume. The detailed deduction of $\left(18_{v}\right)=(6 \mathrm{~S})$, is therefore supplemented here.

Upon normal force $\left(F_{\mathrm{N}}\right)$ application the spherical indentation couples the volume formation $(V)$ with pressure formation to the surrounding material + pressure loss by plasticizing ( $\left.p_{\text {total }}\right)$. One writes therefore Equation (1S) (with $m+$ $n=1)$

$$
F_{\mathrm{N}}=F_{\mathrm{Nv}}^{m} F_{\mathrm{Nptotal}}^{n}
$$

There can be no doubt that the total pressure depends on the inserted calotte volume that is $V=h^{2} \pi(R-h / 3)$. It is multiplied on the right-hand side with $1=$ $h / h$ to obtain (2S). We thus obtain (3S) and (4S) with $n=1 / 3$.

$$
V=h^{3} \pi(R / h-1 / 3)
$$




$$
\begin{gathered}
F_{\text {Nptotal }} \propto h^{3} \\
F_{\text {Nptotal }}^{1 / 3} \propto h_{p \text { total }}
\end{gathered}
$$

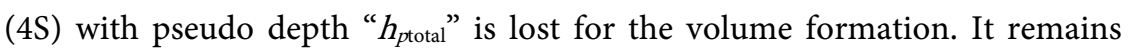
(5S) with $m=2 / 3$ on $F_{\mathrm{N} V}$ or the exponent $3 / 2$ on $h_{v}$.

$$
F_{\mathrm{N} v}^{2 / 3} \propto h_{v} \text { or } F_{\mathrm{N} v} \propto h_{v}^{3 / 2}
$$

The proportionality (5S) must now result in an equation by multiplication with the dimensionless correction factor $\pi(R / h-1 / 3)$ and with a materials' factor $k_{v}\left(\mathrm{mN} / \mu \mathrm{m}^{3 / 2}\right)$ to obtain Equation (6S) that is Equation (18) in the main paper.

$$
F_{\mathrm{N} v}=k_{v} h^{3 / 2} \pi(R / h-1 / 3)
$$

For plotting of (6S) for obtaining $k_{V}$ the $\pi(R / h-1 / 3)$ factor is separately multiplied with $h^{3 / 2}$ for every data pair.

An additive term $F_{\mathrm{a}}$ can be necessary for the axis cut correction if not zero due to initial surface effects of the material. 